\title{
Association of Testosterone Level among Lepromatous and Borderline Leprosy Male Patients: Experience of 30 Cases in Bangladesh
}

\author{
Abu Sayeed Mohammad ${ }^{1}$, Tarequzzan $\mathrm{Mia}^{2}$, MA Hamid ${ }^{3}$, Shahadat Hossain ${ }^{4}$, Zulfiqur Hossain Khan ${ }^{5}$ \\ ${ }^{1}$ Associate Professor, Department of Dermatology \& Venereology, Mugda Medical College, Dhaka, Bangladesh; ${ }^{2}$ Assistant \\ Professor, Department of Dermatology \& Venereology, Shaheed Suhrawardy Medical College, Dhaka, Bangladesh; ${ }^{3}$ Assistant \\ Professor, Department of Dermatology \& Venereology, Mugda Medical College, Dhaka, Bangladesh; ${ }^{4}$ Professor \& Head, \\ Department of Dermatology \& Venereology, Shaheed Suhrawardy Medical College, Dhaka, Bangladesh; ${ }^{5}$ Professor \& Head, \\ Department of Dermatology \& Venereology, Mugda Medical College, Dhaka, Bangladesh
}

[Received: 12 July 2020; Accepted: 30 August 2020; Published: 1 December 2020]

\begin{abstract}
Background: Hormonal dysfunction is reported among the leprosy patients. Objective: The purpose of the present study was to see the association of testosterone level among male patients presented with lepromatous and borderline leprosy. Methodology: This cross-sectional study was conducted in the Leprosy Hospital, Dhaka, Bangladesh from January to December 2016 for a period of one year. All patients with a known diagnosis of leprosy under follow up at the hospital were included in the study. The serum concentration of testosterone was measured using an enzyme immunoassay technique (ELISA) (DiaMetra, Spello, Italy). Result: A total number of 30 cases of leprosy were recruited for this study. The mean with SD of the study population was $39.20 \pm 9.065$ years. Among 30 cases of study population 26 cases were lepromatous leprosy patents and the rest 4 cases were Borderline Leprosy patients. The mean with the standard deviation of testosterone level in serum was $6.41 \pm 4.756 \mathrm{mg} / \mathrm{dL}$ and $4.71 \pm 2.396 \mathrm{mg} / \mathrm{L}$ in lepromatous leprosy and borderline leprosy respectively $(\mathrm{p}=0.497)$. Conclusion: In conclusion there is no statistically significant relationship between leprosy and testosterone; however, lower level of testosterone is found among the study population. [Bangladesh Journal of Infectious Diseases, December 2020;7(2):3639]
\end{abstract}

Keywords: Association; testosterone level; lepromatous; borderline; leprosy

Correspondence: Dr. Abu Sayeed Mohammad, Associate Professor, Department of Dermatology \& Venereology, Mugda Medical College, Dhaka, Bangladesh; Email: dr.sayeed256@gmail.com; Cell no.: +8801817519256

Conflict of interest: Authors declare that there is no conflict of interests.

Funding agency: The study was not funded by any authority.

Contribution to authors: Mohammad AS, Mia T involved in protocol preparation, data collection and literature search up to manuscript writing. Hamid MA, Hossain S, Khan ZH involved in literature search, preparation and revision of this manuscript.

How to cite this article: Mohammad AS, Mia T, Hamid MA, Hossain S, Khan ZH. Association of Testosterone Level among Lepromatous and Borderline Leprosy Male Patients: Experience of 30 Cases in Bangladesh. Bangladesh J Infect Dis 2020;7(2):3639

Copyright: $\odot 2020$. Mohammad et al. Published by Bangladesh Journal of Infectious Diseases. This article is published under the Creative Commons CC BY-NC License (https://creativecommons.org/licenses/by-nc/4.0/). This license permits use, distribution and reproduction in any medium, provided the original work is properly cited, and is not used for commercial purposes. 


\section{Introduction}

Leprosy is a chronic, granulomatous disease prevalent in India and other third world countries ${ }^{1}$. Leprosy and tuberculosis are the two common mycobacterial diseases leading to significant morbidity and mortality in our country ${ }^{2}$. The social stigma attached to the disease persists despite a lot of advances in the management of the disease. The disfigurement and disabilities are the major reasons behind the social stigma of the disease ${ }^{3}$. The disease is caused by mycobacterium leprae and the classical sites of involvement are skin and peripheral nerves ${ }^{4}$. Though the disease manifests predominantly in peripherally visible organs, it involves other internal organs also. Endocrine disorders are often silent, unreported and remain undiagnosed in patients of leprosy ${ }^{5}$.

Endocrine disorders in leprosy result from the direct involvement of the tissue or due to the alteration in immune response. Infection with lepra bacilli is characterized by the changing immune response as a spectrum of the disease activity ${ }^{6}$. The commonly reported endocrine disorders in leprosy include hypogonadism, infertility and osteoporosis. These disorders usually occur late in the course of the disease and are often asymptomatic. The pathogenic mechanism of tissue destruction includes the altered immune response mediated by the inflammatory cytokines and local changes due to endarteritis and fibrosis ${ }^{7}$. Hypogonadism and infertility are the common observations in patients of leprosy. The gonadal involvement is common because testes may act as the reservoir for the lepra bacilli. This present study was undertaken to see the association of testosterone level among male patients presented with lepromatous and borderline leprosy.

\section{Methodology}

This analytical cross-sectional study was conducted in the Leprosy Hospital, Dhaka, Bangladesh. It was a tertiary level referral hospital in Bangladesh. This study was carried out from January to December 2016 for a period of one year. All patients with a known diagnosis of leprosy under follow up at the hospital were included in the study. This study was included male patients affected by leprosy. Recruitment was through consecutive sampling. The newly diagnosed patients and also the patients on regular follow-up were included. Leprosy was diagnosed based on the presentation, clinical examination, and skin biopsy findings. Exclusion criteria were patients with known thyroid or endocrine disorders, diabetes, tuberculosis, or a hepatic or renal disease, as determined through history-taking and physical examination, patients with a history of chemotherapy or radiotherapy and patients who had a history of parotitis and testicular abnormalities due to a genetic disorder. All patients were subjected to careful history-taking, physical examination, local genital examination, laboratory investigations, and testicular ultrasonography examination. The serum concentration of testosterone was measured using an enzyme immunoassay technique (ELISA) (DiaMetra, Spello, Italy).

Statistical analysis: The statistical analysis was conducted using IBM SPSS Statistics version 24.0 for Windows (IBM Corp., Armonk, NY, USA). All data collected were then manually added to the patient's medical records, and the information was processed and analyzed using a descriptive approach. The data were presented as the percentage for categorical variables and as the mean \pm standard deviation (SD) and range for numerical variables. Student $t$ test was performed to see the level of significance. $\mathrm{P}$ value less than 0.05 was taken as statistically significant.

Ethics Statement: The study was approved by the Local Ethics Committee of Leprosy Hospital. The patients were informed that they could withdraw from the study at any time. Patient information was kept confidential. Written consent for participation in the study was obtained from each participant in their local language.

\section{Result}

A total number of 30 cases of leprosy were recruited for this study after fulfilling the inclusion and exclusion criteria. In this study less than 35 years was in $10(33.3 \%)$ cases and more than 35 years was in 20(66.7\%) cases. The mean with SD of the study population was $39.20 \pm 9.065$ years with the range of 22 to 56 years. The median age of the study population was 40.0 years (Table 1 ).

Table 1: Age Distribution of Study Population $(\mathbf{n}=30)$

\begin{tabular}{|l|c|c|}
\hline Age Group & Frequency & Percent \\
\hline Less Than 35 Years & 10 & 33.3 \\
\hline More Than 35 Years & 20 & 66.7 \\
\hline Total & $\mathbf{3 0}$ & $\mathbf{1 0 0 . 0}$ \\
\hline Mean \pm SD (Range) & $39.20 \pm 9.065(22-56)$ \\
\hline
\end{tabular}

Among 30 cases of study population 26 cases were lepromatous leprosy patents and the rest 4 cases were Borderline Leprosy patients. The mean with 
the standard deviation of testosterone level in serum was $6.41 \pm 4.756 \mathrm{mg} / \mathrm{dL}$ and $4.71 \pm 2.396 \mathrm{mg} / \mathrm{L}$ in lepromatous leprosy and borderline leprosy respectively. The difference of serum testosterone level between lepromatous leprosy and borderline leprosy was not statistically significant $(\mathrm{p}=0.497)$ (Table 2).

Table 2: Association of serum Testosterone with Leprosy $(n=30)$

\begin{tabular}{|l|c|c|c|}
\hline \multirow{2}{*}{ Leprosy } & \multicolumn{2}{|c|}{$\begin{array}{c}\text { Testosterone } \\
\text { Level }\end{array}$} & \multirow{2}{*}{ P value } \\
\cline { 2 - 3 } & Mean & SD & \\
\hline Lepromatous $(\mathrm{n}=26)$ & 6.41 & 4.756 & \multirow{2}{*}{0.497} \\
\hline Borderline $(\mathrm{n}=4)$ & 4.71 & 2.396 & \\
\hline Total $(\mathrm{n}=30)$ & 6.187 & 4.5204 & \\
\hline
\end{tabular}

$\mathrm{SD}=$ Std. Deviation

\section{Discussion}

The testicles are among the most commonly involved organs in leprosy ${ }^{8}$. Previously it has been found that leprosy affects the testicles. Testicular volume is correlated significantly with testosterone levels ${ }^{9}$. Therefore, the measurement of testicular volume by ultrasonography may be an important clinical tool to identify those at risk of testicular atrophy. In the current study, it was found that $93.75 \%$ of the patients had reduced testicular volume.

This is a high percentage compared to those reported in other studies, which have found testicular involvement in $10.0 \%$ to $50.0 \%$ of cases $^{10}$. It was found that more of our patients presented with testicular atrophy as the disease progressed. A total number of 30 cases of leprosy were recruited for this study after fulfilling the inclusion and exclusion criteria. In this study less than 35 years was in $10(33.3 \%)$ cases and more than 35 years was in $20(66.7 \%)$ cases. The mean with SD of the study population was $39.20 \pm 9.065$ years with the range of 22 to 56 years. The median age of the study population was 40.0 years

Among 30 cases of study population 26 cases were lepromatous leprosy patents and the rest 4 cases were Borderline Leprosy patients. The mean with the standard deviation of testosterone level in serum was $6.41 \pm 4.756 \mathrm{mg} / \mathrm{dL}$ and $4.71 \pm 2.396 \mathrm{mg} / \mathrm{L}$ in lepromatous leprosy and borderline leprosy respectively. The difference of serum testosterone level between lepromatous leprosy and borderline leprosy was not statistically significant $(p=0.497)$ Testosterone is the most important testicular androgen in men. Testosterone levels decrease about $1.0 \%$ per year after the age of 40 years, while in leprosy patients, serum testosterone levels decrease as a result of testicular atrophy.

The hormone inhibin is secreted primarily by Sertoli cells in the seminiferous tubules ${ }^{11}$. The functions of this hormone include suppressing FSH secretion and inhibiting mammotropic hormone. The absence of this hormone due to hyalinization of the seminiferous tubules results in an increase in the production of FSH and gynecomastia? Gynecomastia was reported in $25 \%$ of lepromatous leprosy patients in the study by Abd-Elkawi et $\mathrm{al}^{2}$ and in $27.0 \%$ of lepromatous leprosy patients in the study by Abd-Elkawi et $\mathrm{al}^{2}$. This is similar to the present study.

The clinical manifestations vary across studies according to the factors affecting testicular atrophy. Testicular involvement in leprosy might occur in the absence of signs and symptoms ${ }^{12}$. The repeated measurement of testosterone levels over the course of the disease may be needed to confirm the testicular atrophy ${ }^{13}$.

The higher frequency of signs and symptoms in patients with low testosterone levels are not observed in this study. These symptoms are present in accordance with the degree of severity of low testosterone. However, the presence of signs and symptoms with abnormal hormone levels definitely indicate testicular atrophy.

\section{Conclusion}

In conclusion most of the leprosy are in the middle age group patients. The testosterone level and association of leprosy is not statistically significant. The level of testosterone is lower among the leprosy patients. The exploration of this reason is necessary. There may be different causes. Therefore, further large scale study should be conducted among the Bangladeshi people.

\section{References}

1. Rea TH. A comparative study of testicular involvement in lepromatous and borderline lepromatous leprosy. International Journal of Leprosy and Other Mycobacterial Diseases: Official Organ of the International Leprosy Association. 1988;56(3):383-8

2. Abd-Elkawi FA, Bahgat SA, Kamel AM, Farag AS, Ashor OM. Testicular function in male patients with lepromatous leprosy. Egyptian Journal of Dermatology and Venerology. 2014;34(1):41

3. de Oliveira Andrade LJ, Oliveira MF, França LS, de Sousa AL, Andrade CS, de Jesus HB. Hypogonadism in leprosy males. Revista de Ciências Médicas e Biológicas. 2012;11(1):60-3

4. Atiqur-Rahman MO. Testicular dysfunction in men affected by lepromatous leprosy. Lepr Rev. 2017;88:258-64

5. Gunawan H, Achdiat PA, Rahardjo RM, Hindritiani R, Suwarsa O. Frequent testicular involvement in multibacillary leprosy. International J Infect Dis 2020;90:60-4 
6. Singh RK, Bhasin R, Bisht YS, Kumar KH. Endocrine dysfunction in patients of leprosy. Indian Journal of Endocrinology and Metabolism. 2015;19(3):369

7. Aglamis E, Tasdemir C, Yucel MO, Ceylan C, Erden I. Prostatic and testicular parameters in lepromatous patients. Lepr Rev. 2014;85:48-53

8. Achdiat PA, Fadilla YO, Gunawan H, Suwarsa O. Testicular atrophy and its clinical manifestations in a patient released from leprosy treatment. Lepr Rev. 2018;89:83-6

9. Maheswari, K.H., 2012. A clinico pathological study of leprosy (Doctoral dissertation)

10. Poudel A, Shah A, Khatiwada S, Samdurkar A. ClinicoPathological Correlation in the Classification of Leprosy.
Journal of Universal College Medical Sciences. 2019;7(2):21-4 11. Tiwari M, Ranabhat S, Maharjan S. Clinicohistopathological correlation of leprosy: A retrospective study of skin biopsy specimens in Chitwan Medical College. International Journal of Medical Science Research and Practice. 2015 Jan 31;2(1):8-11

12. Foss NT, Motta AC. Leprosy, a neglected disease that causes a wide variety of clinical conditions in tropical countries. Memórias do Instituto Oswaldo Cruz. 2012;107:2833

13. Saporta L, Yuksel A. Androgenic status in patients with lepromatous leprosy. British Journal Urology. 1994;74(2):2214 